\title{
THE LIFE HISTORY OF PATINA PELLUCIDA (L.).
}

\author{
By Alastair Graham, D.Sc., and Vera Fretter, Ph.D. \\ Department of Zoology, Birkbeck College, University of London
}

(Text-figs. I-6)

An opportunity to examine specimens of Patina in large numbers presented itself when Dr M. W. Parke and Miss E. Clay, B.Sc., who have been carrying out special research on algae at the Plymouth Marine Laboratory, offered to let us have all the limpets which they collected during their periodical examinations of Laminaria at Wembury, south Devon, and on the west coast of Scotland. The value of the specimens was enhanced by the fact that they were accompanied by notes on the locality of collection, the precise habitat of each mollusc and by the date of collection. This has permitted us to work out the life history of Patina with greater accuracy than has been possible before, and to come to some conclusions regarding the specific nature of populations of this limpet. We would express our great indebtedness to Dr Parke and Miss Clay for the material they so willingly supplied and for help provided on many occasions, as well as to Birkbeck College for a grant of $£$ Io towards the cost of publication.

As is well known Patina is a small limpet found growing on Laminaria spp. and occasionally on other weeds such as Fucus, whilst the youngest stages are also to be found on the rocks and stones of the shore. It occurs in two distinct facies of which one is a characteristic inhabitant of the fronds of Laminaria, and the other is restricted to caves which it excavates for itself on the base of the holdfast, directly under the stipe, or on the outside of the lowest part of the latter. The taxonomic relationships of these two forms have been a matter of argument and have been decided in different ways by different authorities: Forbes \& Hanley (1853) and Jeffreys (1865) both place the two types in the one species pellucida, but the more recent lists of Winckworth (1932) and Eales (1939) regard them as separate species, and call the form from the frond pellucida and that out of the holdfasts laevis, using for this the name first employed by Pennant (1777).

The differences between the two forms of Patina are not merely of habitat, but extend to the shell and animal as well, the points of contrast of the shells of the two types, however, being much more pronounced than those affecting the soft parts. With regard to the latter the most marked difference is in the coloration, animals from fronds being invariably more pigmented than those from the holdfasts, probably because of their greater exposure to light. This, 
in its turn, depends in part upon the most conspicuous difference in the shell of the two (Fig. I). In pellucida the shell is invariably smooth, rather regularly oval in outline (breadth $/$ length $=0.688$, S.D. $=0.139$, range $0.56-0.85$ ), rather low and stream-lined when seen in profile (height $/$ length $=0.273$, S.D. $=0.057$, range $0.13-0.60$ ), and of a clear horn colour and texture, sufficiently transparent to allow of the general disposition of most of the viscera being made out and for such things as the pigmented margin of the attachment of the shell muscle to be quite a conspicuous feature of the appearance of the animal when alive.

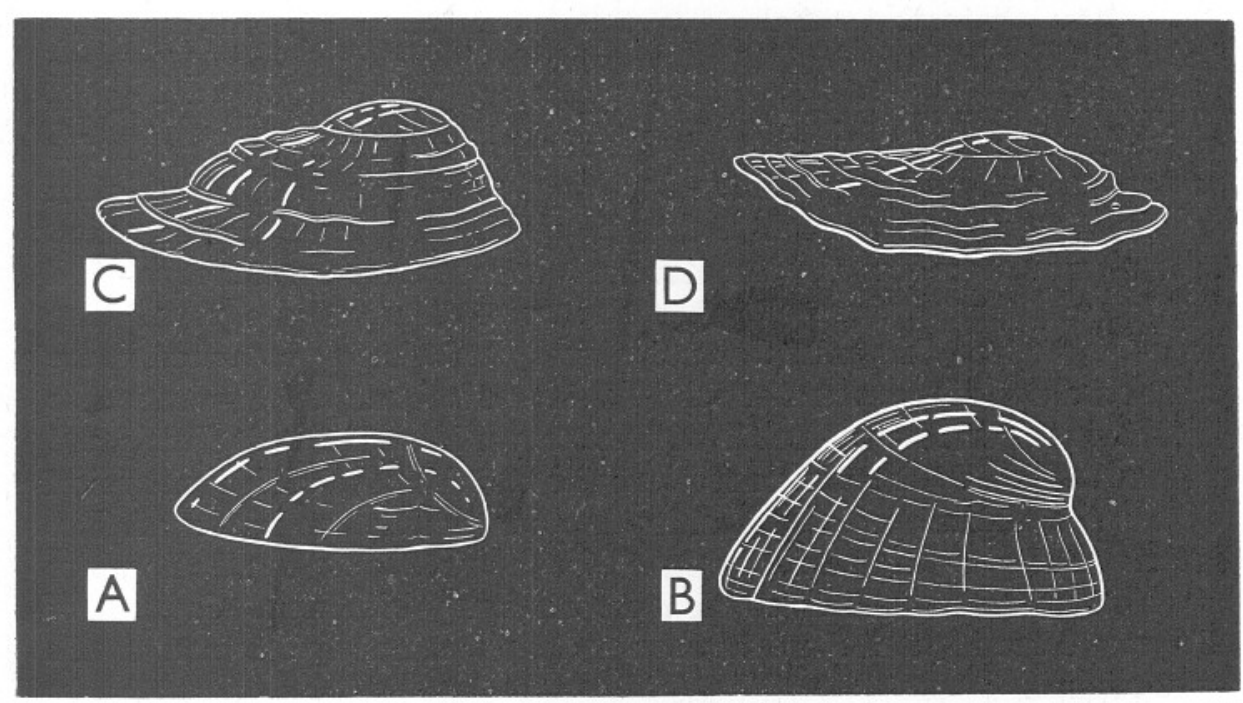

Fig. I. Silhouettes of four types of shells. $\times$ about 6 . A, young pellucida from frond of Laminaria; B, old pellucida from frond of Laminaria; C, D, two shapes of laevis from holdfast of Laminaria.

The apex of the shell is placed close to the anterior margin, which it overhangs almost vertically, and the mouth of the shell has a lip lying all in one plane, as might be expected in an animal which lives on a flat surface such as the frond of Laminaria. Two black or brown marks overlying accumulations of pigment in the underlying mantle are generally pronounced, one a spot near the apex of the shell, the second a streak running in an antero-posterior direction and placed about its centre. The beautiful blue-green rays, which are rather variable in number, ranging from 2 to 8 , are very prominent against the brown background provided by the rest of the shell and this is usually without epizoic growths of any kind.

In laevis, which grows mainly on the holdfast of the weed, the shell is of much more variable shape and two silhouettes of frequent occurrence are shown in Fig. I C, D. It is usually more nearly circular in outline than is 
pellucida (breadth/length $=0.8 \mathrm{I} 8$, S.D. $=0.183$, range $0.45-0.95$ ) and is frequently higher for a given length than is that variety (height/length $=0.344$, S.D. $=0.083$, range $0.17-0.57$ ), the apex of the shell is more nearly central, though never absolutely so, and the mouth is never an opening with a plane lip, but would fit against a concave surface such as is offered by the hemispherical caves in which the creature lives. The most marked difference affects the substance of the shell, which is thick and obviously calcareous in composition and of a pale brown or greenish brown ground colour against which the blue-green rays are often very inconspicuous, whereas reddish brown lines, alternating with the green ones, are much more obvious, especially in the anterior half of the shell and towards the margins: these red lines are apparently not usually present in pellucida at all, having been observed only once. The number of blue-green lines is often much greater than in pellucida and may rise to as many as forty-six. The growth of these shells has often clearly been more irregular than that of pellucida and, while circular striae, lines of growth, are here a regular occurrence in contrast to the almost polished surface of pellucida there are often also great steps and ledges marking irregular growth. One such change is always particularly pronounced in the neighbourhood of the apex of the shell. This area is found, on examination, to be formed of a small smooth shell, with the proportions of that of pellucida, and with radiating blue lines but no red ones; beyond this the shell has the typical appearance of laevis and the transition line between the two is marked. The internal dark spots of pellucida are here faint or even absent, but the nacreous layer is on the other hand much more brilliantly iridescent. Growths of Polyzoa, Serpulid worms and small barnacles are extremely common on this type of shell.

So far as the soft parts of the animals are concerned it is not easy to find any but trifling differences between the two types. The mantle of pellucida has invariably the squarish blot of jet-black pigment in the roof of the pallial cavity and the longitudinal streak over the posterior half of the visceral hump which underlie corresponding pigmented regions of the shell, whilst these marks are at most very poorly developed in laevis. The other external characteristics appear to be identical in the two kinds of animals, though we have a suspicion that the branchial leaflets of the frond-dwelling type are relatively smaller than those of the animals living inside the holdfasts, a point which may be correlated readily enough with the greater exposure to which they are subject. The general arrangement of the viscera is the same in both, though the proportions of the parts vary with the proportions of the shell. In addition, the elaborate coiling of the intestinal region of the gut is modified so as to allow of proper packing within the available space: this is clearly seen in Fig. 2. If the coiling of the two types be analysed it will be found that in both the general plan is the same, but that the exact disposition of the coils varies so as to give in the one a lay-out elongated in one direction and in the other in a 
direction at right angles to that. This is achieved mainly by the altering of the two coils which are numbered 3 and 6 in the figure; in pellucida coil 3 is flung in an anterior direction, whilst in laevis it remains alongside the others; and coil 6, which forms a small, slightly isolated loop in pellucida, is in the other type a narrow transverse coil, again more nearly parallel to the others. It will be noticed, too, that the exact stratification of the coils differs: for example, the stretch of oesophagus running back to the stomach of pellucida is the most ventral of all the parts shown, whereas in laevis no less than three loops pass between it and the foot. These differences, however, are clearly not of great moment and are no more than might be anticipated in animals of such varying shape. Slight variation is, in fact, found amongst the different shapes of the thick-shelled laevis.
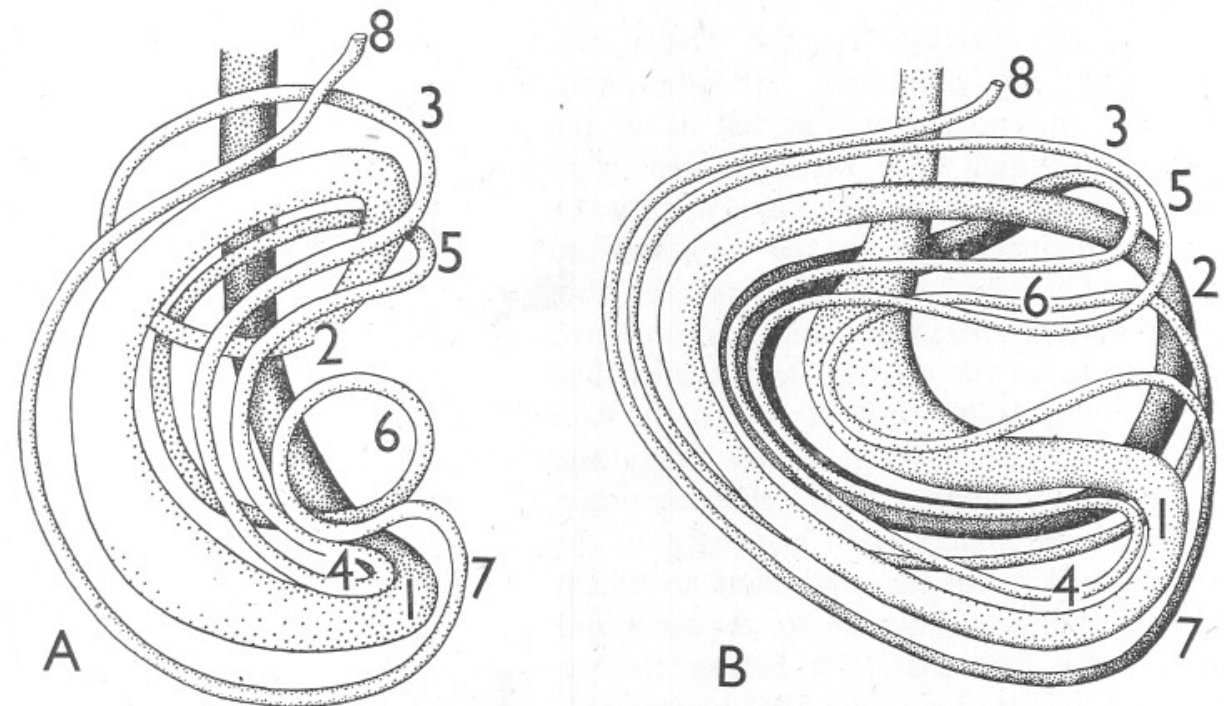

Fig. 2. Diagrams showing the coiling of the gut; A, of pellucida; B, of laevis. I-7, coils; I, the stomach; 8 , the anus. $\times$ about Io.

The radula (Fig. 3) has apparently the same arrangement in both thick- and thin-shelled varieties and bears a close similarity to that of Patella. The central tooth is minute, the outermost lateral has three denticles, and there are regularly three (in one example observed, four) uncoloured marginals beyond that. A comparison of the wear shown by the most anterior teeth in both habitats indicated a clearly greater degree in those animals found in the holdfasts. These are patently feeding on the tissue of the stipe of the weed which they undercut: their diet, living where they do, must be one of more or less undiluted Laminaria. The animals living on the fronds, however, whilst obviously from the appearance of the weed using that for at least part of their nourishment, are also, from the contents of their gut, ingesting vast quantities 
of other material in much the same way as their relative Patella. It is quite probable that the intake of diatoms and similar food from the soft and slimy surface of the Laminaria is a method of feeding which is less destructive of the radular teeth than the direct feeding on the weed, which seems to be the main method followed in the holdfast.

The animals seem to be ripe from lengths of about $5 \mathrm{~mm}$. upwards, so far as can be estimated from an examination of preserved specimens.

All the specimens were classified as either the 'thin' pellucida type or as of the 'thick' laevis type. They were then measured to the nearest tenth of a millimetre for length, breadth and height of the shell, the animals taken out, and the shell weighed after careful removal, under a binocular microscope, of any encrusting growth.

The classification of the shells was normally an extremely straightforward matter, and no doubt was felt as to the group to which each belonged. In every one of these clear examples, too, there was a sharp distinction as to the habitat from which the animal had come: all the thin clear-shelled specimens had been collected on fronds, all the opaque thick-shelled had been living in the holdfasts or on the base of the stipe, suggesting, as was previously indicated by Boutan (1897), that the origin of these differences is to be sought in the varying microclimates and diets to which the two kinds of animals are exposed, and not to the fact that they belong to two distinct species. Of a total of 684 examined, $444(=64.8 \%)$ were of the thin type,

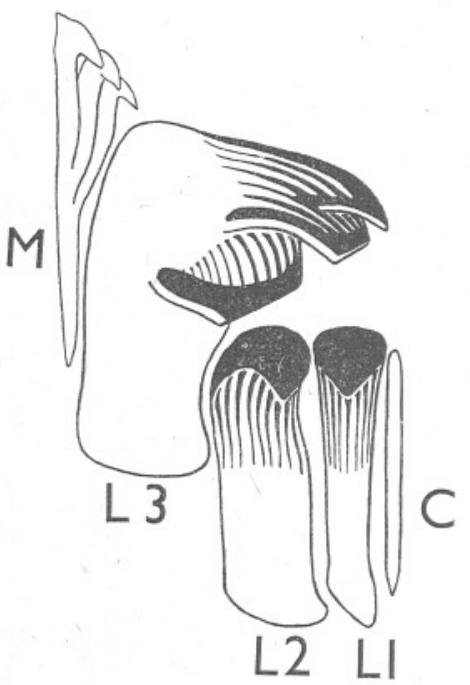

Fig. 3. One half-row of radular teeth, not yet in use, from laevis. C, central tooth; $\mathrm{L}_{1}, \mathrm{~L}_{2}, \mathrm{~L}_{3}$, lateral teeth; $M$, marginal teeth. I99 $(=29.5 \%)$ were of the thick type, whilst $4 \mathrm{I}(=5.8 \%)$ were sufficiently intermediate in their appearance for it to be impossible to decide which they were. Almost half of the latter animals were living in holes on the stipe, the rest living more or less evenly divided between frond and holdfast. In many instances, therefore, those animals of intermediate structure come from a habitat also intermediate in its characteristics, and so again support Boutan's view that exposure and habitat are the factors responsible for the differentiation of the two main types. These intermediate shells were not used for later work.

When the shells are sorted into classes according to their length and type, and when the numbers are examined, the results expressed in Fig. 4 are obtained. This gives several pieces of information. It shows that the pro- 
portion of individuals of the thick type is least in the smallest sizes-though this is partly a reflection of the fact that it is most difficult to differentiate clearly between these two types when dealing with the most minute shellsand it suggests that there is only one type in the very smallest and youngest stages. It shows, too, that the proportion of thick shells rises as the age of the animals increases, until amongst the giant shells the thin type forms an unimportant percentage: this may obviously be linked with the much greater probability of frond-dwellers being damaged, swept away from their homes or eaten by predators, than the thick-shelled animals leading a more sheltered

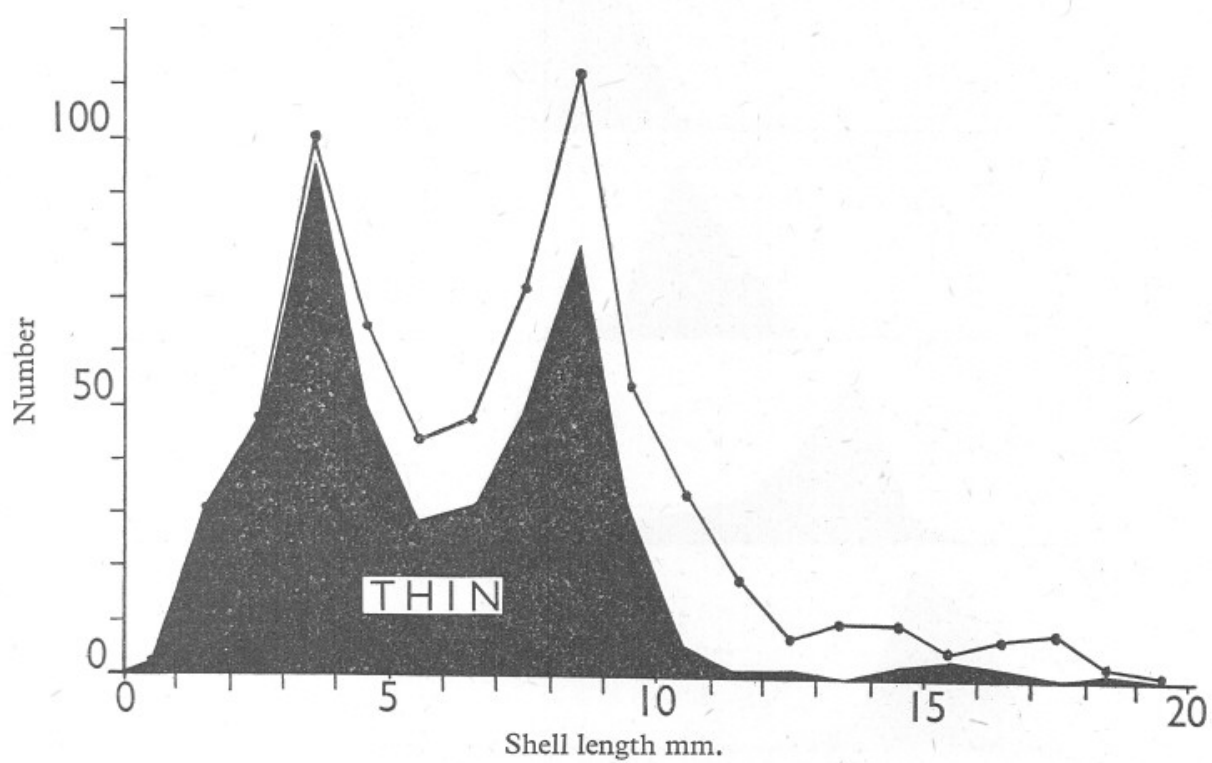

Fig. 4. Size-distribution curve of total number of Patina examined. The upper line gives the total number of animals for each length, the area shaded black the number of thin shells, the area left white therefore showing the number of thick shells.

existence in the holdfasts. The peaks in the curve mainly reflect the seasonal activities of the collectors, but they do indicate that the population of Patina must be made up of age classes, each derived from a single fall of spat.

To explore this question further the shells were next sorted according to the month in which they had been collected, and in this way a series of sizefrequency curves which are shown in Fig. 5 was obtained. In each group of this series the modal class has been represented as Ioo and the other points calculated as percentages. It is clear that the bulk of Patina in May measure $\mathrm{I} \cdot 0-3.0 \mathrm{~mm}$. in length and are presumably the comparatively recently settled spat of the same spring. No collections are available after May until September, 
but here again the shape of the curve shows that the greater part of the population has then a size of $2.5-5.0 \mathrm{~mm}$. length, a growth of $\mathrm{I} \cdot 5-2.0 \mathrm{~mm}$. over a

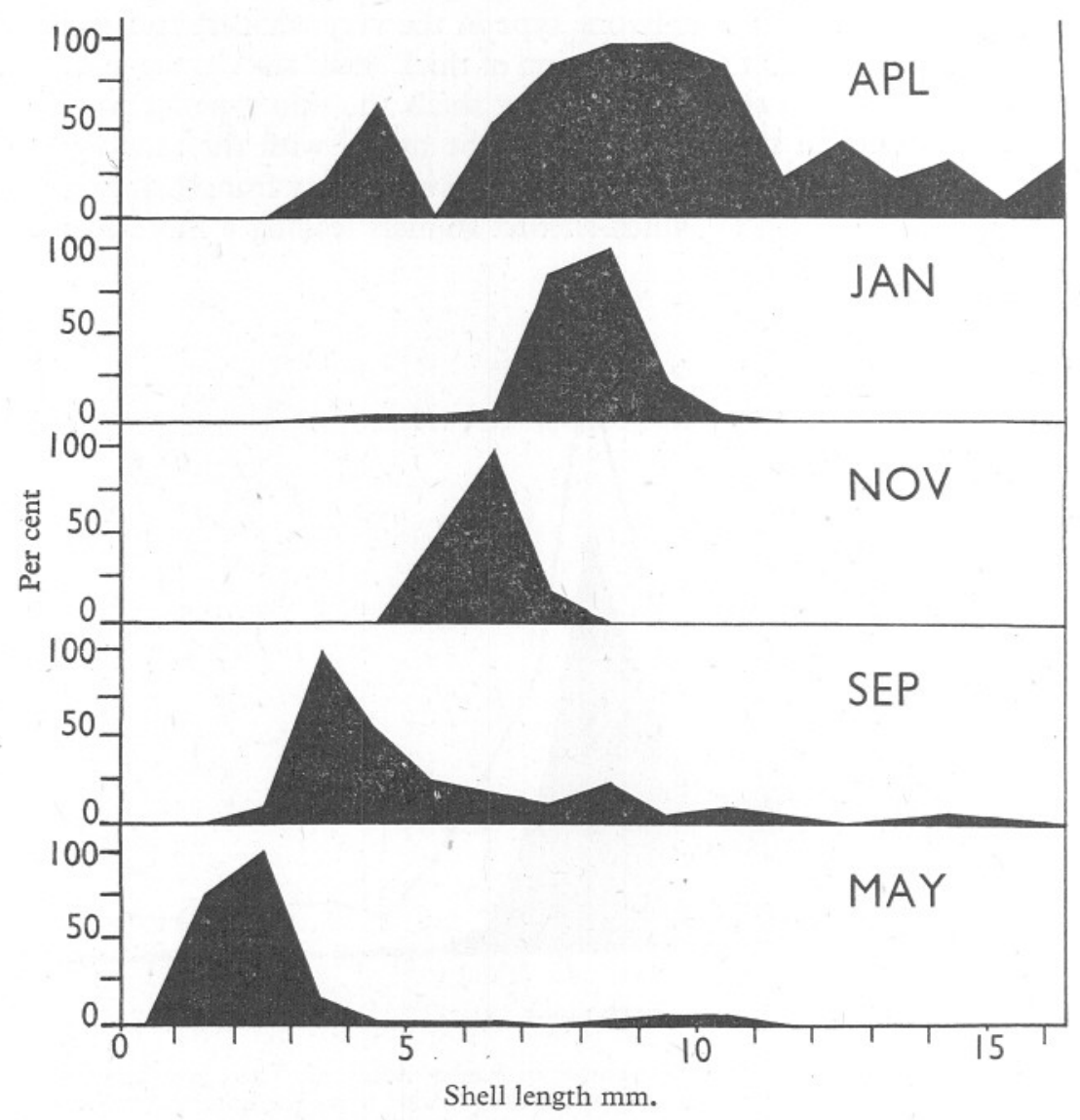

Fig. 5. Size-distribution curves for five months of the year: in each curve the modal point has been made Ioo.

period of four months. By November the modal point has risen to $6.5 \mathrm{~mm}$. length, by January to $8-9 \mathrm{~mm}$., and growth continues during the spring until by April of the next year the population has a modal length of 9-II mm.

$\begin{array}{lcc}\text { Month } & \begin{array}{c}\text { Modal length } \\ \text { (mm.) }\end{array} & \begin{array}{c}\text { Growth } \\ \text { (mm.) }\end{array} \\ \text { May } & 2.5 & - \\ \text { Sept. } & 3.5 & 1.0 \\ \text { Nov. } & 6.5 & 3.0 \\ \text { Jan. } & 8.5 & 2.0 \\ \text { Feb. } & 9.5 & 1.0 \\ \text { Apr. } & 10.0 & 0.5\end{array}$


From this it would appear that a population which is formed in the spring of one year by spatfall from the crop of planktonic larvae has reached a size of about ro mm. length by the same month of the following year, growth being more or less rapid in summer, autumn and early winter months, but reduced to a lower level during the first months of the year. By comparing this with the size distribution over the whole population as shown in Fig. 4, it would seem that the first peak, at $3.5 \mathrm{~mm}$., represents the collectors' haul in summer, the second peak, at $8.5 \mathrm{~mm}$., their catch in early winter. The large reduction in numbers collected of shells of greater size, however, representing animals which must be over one year old, and which would therefore have been captured in May in numbers equal to those of the shells 3-4 mm. long, had they been there to catch, indicates that practically every specimen of Patina dies at an age of about I2 months and that only remnants of the original population survive into a second year. As was remarked above, these are nearly always limpets of the thick-shelled type which have found a sheltered haven in the holdfasts of the weed they inhabit. The rate of growth revealed by these figures for Patina is very noticeably less than those recorded by Orton (I928) for various molluscs, even for such a near relative as Patella, and is still considerably less than the lower figures obtained by Russell (I909) for that animal. It is however much more nearly comparable with those recorded by Moore for Littorina (I936b) and Nucella (I938).

Comparing the weights of shells of similar length belonging to the two types shows (Fig. 6) that the thick type put on weight more rapidly at all stages in the life history, but with increasing speed as they age, so that a shell of the thick type at a length of $9 \mathrm{~mm}$. or more, will weigh at least twice as much as a thin shell of the same length.

If we now attempt to reconstruct the course of the life history of Patina from the data given above it appears as follows. The eggs are laid apparently during any month of the year (at Plymouth) according to Lebour (I937), but there is a spring period during which egg-laying reaches a maximum. We have ourselves found that animals are sexually mature from a length of about $5 \mathrm{~mm}$. This they attain by about November, so that from then into the following spring the entire population will be actively reproducing. The veligers have a short planktonic life-only a few weeks (Lebour, personal communication) and they then metamorphose and settle on whatever substratum is adjacent. These metamorphosed creatures are therefore likely to be found not merely on Laminaria but on other weeds and on rocks as well: it is probably the first group alone, however, that survives, the others dying for lack of proper food after longer or shorter periods, as it is only on Laminaria that individuals more than 3-4 mm. in length can be found. All of these newly settled spat are alike and it is not possible to classify them into thick- or thin-shelled varieties, indicating that their transformation into one or the other of these is a later phenomenon. Amongst those that settle on Laminaria the majority will fall on 
the fronds and will proceed to feed on the surface of these, either on the substance of the weed itself or on the diatoms and similar minute material which may occur on the surface. If they persist in this habitat these limpets will grow, but will retain the thin shell characteristic of the newly metamorphosed animal, and because of the greater exposure of their soft parts to light on this account will become more highly pigmented, whilst because of their greater exposure to wave action their shell will develop into a rather low structure which reduces

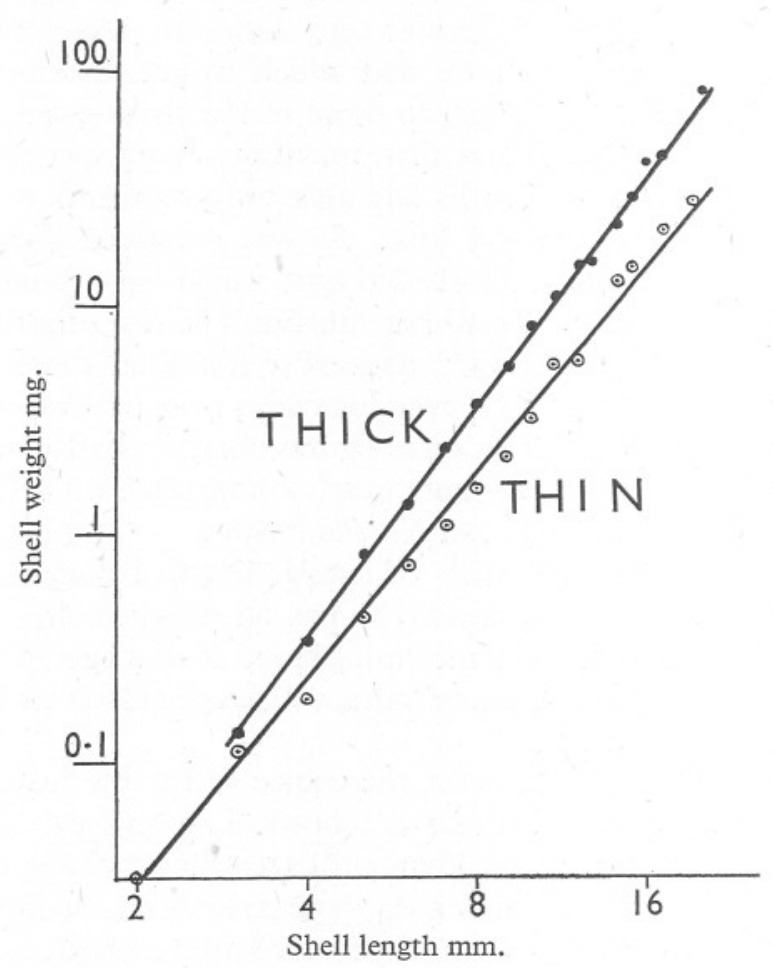

Fig. 6. Relation between length of shell and weight of shell. Plotted logarithmically.

the risk of their being swept away. This shell construction must be due, at least in part, to the nature of their diet; and to that too, as with Nucella (Moore, I936a), the lack of brownish red rays in the shell. Some Patina, on the other hand, will settle on, or may be carried by water currents into, or may actively migrate into, the space inside the holdfast of Laminaria, and these will grow into the thick type with rounder shells, which fit into the more limited space available, and with higher shells because they are much more sheltered from wave action. The shells also, probably because of the different diet of the animals, become much more solidly calcified and have prominent reddish lines in addition to the usual blue. These thicker shells will give extra 
protection to the soft parts against light and will so prevent the development of pigment. That the number of limpets which ultimately end in the holdfasts of Laminaria is greater than the number which originally fall there by chance as spat, and that it is augmented by an active migration of small individuals from the fronds, is indicated by the detailed structure of the shell of most animals of this type: the youngest part has the proportions, the colouring and the texture of the thin type and this changes abruptly at one point to those characteristic of the thick. An analysis of I5O shells of the thick type, selected at random, shows that the change in shell structure indicates a change of habitat at a length of $3 \mathrm{~mm}$. for $16 \%$, at a length of $4 \mathrm{~mm}$. for $46 \%$, of $5 \mathrm{~mm}$. for $26.6 \%$, at $6 \mathrm{~mm}$. for $10 \%$, and that only $\mathrm{I} \cdot 2 \%$ migrate at a greater length. These lengths are reached during the first summer of the animal's life, and the bulk of the migratory movement is over by October-November. It would therefore appear quite definite that there is only the one species of Patina, to which the name pellucida must be applied, whilst laevis is not worthy of specific rank, but is an environmental form induced by the different conditions of food and exposure within the holdfast.

The next point to be considered is the relationship of Patina to the life cycle of the weeds upon which the animals are living. In this respect discussion will be limited to the two species of Laminaria digitata and Cloustoni, and is based on information provided very generously by Dr M. W. Parke and Miss E. Clay. Laminaria digitata has a long fruiting season, with maxima in spring and autumn. After the autumn fruiting is over the upper half of the frond gradually disintegrates and little by little breaks off, after which, in the first few months of the year a new growth occurs, mainly in February, March and April, leading to the production of a new frond for the next season of the plant's growth, though a certain amount of further breakdown occurs after the spring fruiting. If Laminaria fronds be examined in April, say, the young Patina which have just settled thereon are found scttered more or less at random over the surface of the weed upon which they are feeding. It is clear that if they maintain this random distribution over the surface of the frond during the spring breakaway a certain number of limpets will be cast away with the frond and lost: this presumably happens, but the number of limpets so lost will be minimal, as at that time of the year the majority of the animals found on this region of the frond are newly metamorphosed spat, and a much greater number of these will be lost by settling on rocky and other unsuitable substrates where prolonged life is not possible. As the autumn breakdown of the Laminaria is much greater than the spring disintegration the result would then be much more serious to the limpet population, especially as the animals are then preparing for their period of maximum reproduction. This loss, however, is prevented by a downward migration of the limpet which takes place in late autumn: it has the effect of concentrating the animals on the most basal part of the frond which will not be cast off and which will gradually elongate to 
form the weed of the next season. Since the numbers of Patina do not seem to drop off markedly until the spring of the year after that in which they settle as spat, this downward migration is seen as an important reaction on the part of the animal. As it takes place about the time they are becoming sexually mature it is of very great importance as a means of securing a base on which the animal may survive the winter to participate in the spring reproductive maximum. To what, however, does the limpet react? The conclusion would seem inevitable that Patina must be feeding on the weed (and not merely relying on superficial detritus attached to it) to a sufficient extent to make it appreciate changes in the chemical composition of the plant tissue and to respond to changes in the amount of edible material present. Precisely what substance this affects seems to be indefinite, and it might be variation in any one of a series of stored products which causes the downward passage of the limpet-thus Hoffmann (1939) lists variation in the polysaccharide laminarin, in the sugar mannite, and in alginic acid from season to season, and Parke and Clay (in litt.) have found a difference between the amount of fucosan in the younger and older cells of the weed.

Laminaria Cloustoni fruits during the winter, and instead of a gradual disintegration of the frond thereafter, the whole structure is constricted off at its base from the new frond which starts growth in January. The old frond is carried up on the new growth and cast off in spring as 'Mayweed'. The limpets behave on $L$. Cloustoni in a similar manner to L. digitata-migrating downwards in late autumn-but in this species the movement stops when the animals have reached the basal part of the old frond, only a small number getting on to the extreme basal region from which the next year's growth is derived. It is difficult in these circumstances to see how the limpets are not frequently cast off with the remains of the old frond, but as this does not occur until late spring or early summer the breeding period will then be over and the animals are probably exhausted and moribund whatever happens.

\section{SUMMARY}

Patina pellucida occurs in two facies with characteristics of habitat and structure, the latter' affecting mainly the shell. One variety, pellucida, which lives on the fronds of Laminaria, has a smooth, elongated oval and low shell, which is transparent and brown in colour, with 2-8 blue rays radiating backwards from the summit which is placed at the anterior end; it is normally devoid of either epiphytic or epizoic growth. The soft parts are pigmented because of the translucency of the shell, the radular teeth only slightly worn, and the arrangement of the gut coils adapted to a long, narrow haemocoelic space.

The second variety, laevis, lives in caves in the holdfasts of Laminaria, and has a rough, round and usually high shell, though the proportions are more variable than in the variety pellucida. The shell is opaque and brown in colour, with 2-46 blue rays and also red-brown ones more or less regularly alternating 
with them; it has a central summit and is frequently covered with growths of various sorts. The soft parts are not pigmented, the radular teeth are considerably worn, and the coiling of the gut modified to fit into the rounder haemocoel.

The life history may be summarized: the animals breed maximally in winter and spring, the planktonic larvae settling mainly in May as spat about $2 \mathrm{~mm}$. in length. They grow so as to reach a length of about $5 \mathrm{~mm}$. in the following autumn and Io mm. after a year of sedentary life, becoming sexually mature at $5 \mathrm{~mm}$. length. The majority of the animals die after a settled life of $\mathrm{I} 2$ months, but a few linger on into a second year: nearly all these belong to the variety laevis, living a sheltered life within the holdfast of the weed, not exposed like pellucida to the effects of wave action and storm.

When the larvae fall as spat all are at first alike, with the characteristics of pellucida. If they stay on the fronds these persist into the adult stage; if, however, they migrate into the holdfasts, the influence of the changed surroundings and diet evokes the characteristics of laevis; this migration occurs during the animal's first summer.

The idea that there are two species of Patina would thus appear to be wrong: there are two varieties of the nature of ecotypes.

The life history of the variety pellucida involves a downward migration on the fronds of Laminaria. When the species is L. digitata this migration brings the limpets on to the next season's frond and prevents them being cast off when the weed has fruited.

\section{REFERENCES}

Boutan, L., I897. L'organe glandulaire périphérique de l'Helcion pellucidum (Lin.). Arch. Zool. gén. exp., 3me série, T. 5, pp. 437-82.

Eales, N. B., I939. The Littoral Fauna of Great Britain. Cambridge.

Forbes, E. \& Hanley, S., I853. A History of British Mollusca and their Shells. London.

Hoffmann, C., I939. Die praktische Bedeutung der Meeres-algen. Kieler Meeresforschungen, Bd. 3, pp. 165-232.

Jefrereys, J. G., 1865. British Conchology. London.

Lebour, M. V., I937. The eggs and larvae of the British prosobranchs with special reference to those living in the plankton. Fourn. Mar. Biol. Assoc., Vol. 22, pp. $105-66$.

Moore, H. B., I936a. The biology of Purpura lapillus. Part I. Shell variation in relation to environment. Fourn. Mar. Biol. Assoc., Vol. 21, pp. 6I-89.

- I $936 \mathrm{~b}$. The biology of Littorina littorea. Part I. Growth of the shell and tissues, spawning, length of life and mortality. Fourn. Mar. Biol.Assoc., Vol. 21, pp. 72 I-42.

- 1938. The biology of Purpura lapillus. Part II. Growth. Fourn. Mar. Biol. Assoc., Vol. 23, pp. 57-66.

Orton, J. H., I928. Observations on Patella vulgata. Part II. Rate of growth of shell. Fourn. Mar. Biol. Assoc., Vol. 15, pp. 863-74.

Pennant, T., I777. British Zoology. London.

Russell, E. S., I909. The growth of the shell of Patella vulgata. Proc. Zool. Soc. London, I909, pp. 235-53.

Winckworth, R., I932. The British marine Mollusca. fourn. Conch. Vol. I9, pp. $2 \mathrm{II}-52$. 